\title{
NOTAS SOBRE A TEORIA DA NORMATIVIDADE TÉLICA: UM NOVO CAPÍTULO DA EPISTEMOLOGIA DAS VIRTUDES DE ERNEST SOSA*
}

\author{
João Carlos Salles** \\ http://orcid.org/0000-0002-4872-3465 \\ jcsalles@gmail.com
}

To reach Larissa through ignorant luck is not to flourish. (Ernest Sosa)

\begin{abstract}
RESUMO Ernest Sosa é um dos mais importantes filósofos da contemporaneidade. Em plena atividade há mais de cinco décadas, sua obra toma agora a forma de uma teoria da normatividade télica, com a qual Sosa pretende coroar sua procura por uma "knowledgefriendly epistemology". Pretendemos mostrar que esta nova forma teórica instala-se bem no conjunto de sua reflexão epistemológica, procurando Sosa agora, de modo ainda mais preciso, dar resposta, por exemplo, às questões decorrentes do problema de Gettier, da intencionalidade e das modalidades epistêmicas. Entre as novidades de sua atual formulação, analisaremos de modo mais especifico neste texto alguns problemas colocados pelo exemplo do arqueiro, ao transformar-se este em um modelo teórico ilustrativo da noção de normatividade télica, bem como alguns aspectos da singular taxonomia do conhecimento feita por Sosa.
\end{abstract}

* Artigo submetido em 23/11/2018. Aprovado em 13/03/2019.

** Universidade Federal da Bahia. Salvador, BA, Brasil. 
Palavras-chave Normatividade télica, epistemologia das virtudes, Ernest Sosa, Gettier.

ABSTRACT Ernest Sosa is one of the most outstanding philosophers in our contemporaneity. Working intensively for over five decades, his work now takes the form of a theory of telic normativity with which he intends to crown his search for a "knowledge friendly epistemology". We intend to show that this new theoretical form is well settled in the whole of his epistemological reflection, being Sosa interested now in providing, more precisely, an answer, for instance, to questions derived from Gettier's problem, from intentionality, and from epistemic modalities. Among the innovations of his present formulation, we shall analyze, more specifically in this text, some problems expressed through the archer's example, when it turns to be an illustrative theoretical model of the telic normative notion, as well as some aspects of Sosa's singular taxonomy of knowledge.

Key words Telic normativity, virtue epistemology, Ernest Sosa, Gettier.

\section{1.}

Ernest Sosa é um dos mais importantes filósofos da contemporaneidade. Em plena atividade há mais de cinco décadas, sua obra constitui um campo próprio de reflexão em diversas áreas, tendo inaugurado, em especial, uma das vertentes mais fecundas da epistemologia das virtudes - vertente que agora, com seu trabalho mais recente, toma a forma de uma teoria da normatividade télica, com a qual coroaria sua procura por uma "knowledgefriendly epistemology: not knowledgefirst but knowledgefriendly". Afinal, como já tem afirmado Sosa, "Our aim is a theory of knowledge that will fit a unified and widescope epistemology” (Sosa, 2017, p. 210).

A expressão 'normatividade télica' (telic normativity) não aparece na obra já publicada de Sosa, sendo porém central em seu novo livro, ainda inédito e em fase de revisão, Epistemic explanations: a theory of telic normativity, and what it explains. Embora não tenha os contornos completamente definidos, nem seja um acréscimo nominal, a noção vê-se naturalmente antecipada na obra, e. g., na ênfase concedida por Sosa "on action that takes a means-end form" ações que comportam intencionalidade, devendo o sucesso em atingir a meta manifestar competência. Assim, conquanto o nome ocorra apenas em trabalho ainda inédito, isso não impede a apreciação de seus méritos e sentidos, pois é uma teoria, digamos, in fieri, estando em progressivo processo de consolidação, 
ao menos desde 2005, com as Locke Lectures, publicadas no livro A Virtue Epistemology (Sosa, 2007) e tendo esboço bastante claro em Judgment \& Agency (Sosa, 2015) e Epistemology (Sosa, 2017).

\section{2.}

O que é, porém, essa normatividade télica que a obra de Sosa, a pouco e pouco, labora e torna central? Ora, em linguística, dizemos 'télico' o verbo que denota uma ação que visa a atingir uma finalidade, encerrando-se ao atingi-la. A normatividade então envolvida caracterizaria todo um conjunto de performances, orientadas a um télos específico e por ele realizadas. Dessa forma, consertar um objeto conclui-se com o conserto; entrar em uma casa com o ter entrado etc. Teríamos aqui talvez uma primeira dificuldade. Afinal, conhecer visa à verdade, mas não se conclui exatamente com tê-la atingido, a menos que incluamos nessa conclusão do ato a permanência da verdade, sua retenção na memória ou em outros registros, bem como os passos derivados de justificar a verdade, ensinar a verdade, ou convencer outras pessoas dessa verdade.

Mais ainda. Sendo o conhecer um misto gramatical de estado e atividade, não deixamos de conhecer algo por esse algo ter sido conhecido, ao contrário de como deixaríamos de consertar um objeto por ele já estar consertado. A dificuldade pode, contudo, ser afastada com alguma facilidade. Tendo isso em conta, ao ser aplicado a ações, ‘télico’ não pretende recobrir a gramática inteira comum a esses verbos, mas antes destaca o movimento orientado e definido por uma finalidade, de sorte que o compreenderíamos melhor, nesse caso, por seu poder referir-se ao que comporta intencionalidade, tendo no seu télos a medida necessária do que é relevante e se mobiliza para seu sucesso, e não exatamente seu encerramento. Finalidade internamente orientada, portanto, é a chave comum às performances humanas a ser destacada, e não seu término, enfatizando-se assim a ideia de intentos cujo êxito manifesta a competência pertinente do agente.

A normatividade télica reconfigura e atualiza um campo de interesse presente em toda a obra de Sosa, qual seja, o das ações intencionais normativas (em particular, as que envolvem a performance singular que chamamos de conhecimento), em relação a cujos fenômenos estabeleceria uma teoria. A normatividade do conhecimento torna-se um caso especial de normatividade télica, sendo o conhecimento um tipo central de sucesso epistêmico, com o qual se podem doravante confrontar as questões tradicionais postas pelo ceticismo e outras relativas à natureza, escopo e valor do conhecimento. Da mesma forma, 
com essa teoria, é possível responder aos diversos casos gettierescos, agora classificados pela condição comum de que neles o agente epistêmico falha, quer por sua crença pertinente estar aquém da aptidão de atingir a verdade pelo exercício de suas virtudes intelectuais, quer por não ser uma realização plenamente competente, na qual o agente saberia avaliar a adequação de sua capacidade e estado à situação em que exercita a procura do conhecimento.

Vale notar que o tema das ações intencionais perpassa a obra de Sosa desde o começo, e sempre marcado por uma pauta gettieresca, mesmo antes de a epistemologia das virtudes tornar-se uma chave para a solução dos enigmas de Gettier. Sosa doutorou-se em 1964, com uma tese sobre a lógica de comandos, na qual realiza uma análise dos imperativos e também da obediência; portanto, de ações intencionais. ${ }^{1}$ Nesse mesmo ano, sua atenção era também capturada pelo problema de Gettier, tendo sido ele o autor de uma das primeiras reações ao problema, para o qual ofereceu, então, em artigo específico, a análise talvez a mais detalhada do que seria uma cláusula adicional à definição de conhecimento, de modo a impedir o indesejável resultado de que o acaso, a sorte, venha a frustrar o conhecimento - exatamente a possibilidade denunciada por Gettier. ${ }^{2}$ Por sua feita, a análise das directives recorre à invenção de exemplos em que a atribuição de obediência é perturbada por alguma deviant causation. Ou seja, a análise de condições necessárias e suficientes para a atribuição de obediência é desafiada por exemplos e contraexemplos, no modo próprio de Sosa (e de grande parte da literatura) de lidar com o problema de Gettier, sobretudo nos anos subsequentes ${ }^{3}$

Entretanto, o exemplo cada vez mais utilizado por Sosa para esclarecer uma típica ação normativa télica, tornando-se, por isso, canônico na obra, não vem dos livros de direito sobre normas, nem dos livros de ciência sobre a

1 Directives: A logico-philosophical inquiry, tese apresentada à University of Pittsburgh em 1964. Por sinal, apesar da mudança significativa no repertório de textos e questões após mais de cinquenta anos, há um livro em comum à bibliografia da tese de 1964 e à de seu mais recente livro publicado, Epistemology, de 2017, e é exatamente o texto clássico de G. E. M. Anscombe, Intention.

2 O jovem doutor imaginou ter podido apresentar "the correct (recursive) definition of "knowledge that p"' (SOSA, E. "The analysis of 'Knowledge that p". Analysis, Vol. 25, Nr. 1, 1964, p. 7). Sabemos agora que a saga só estava começando, tendo Sosa papel destacado em muitos dos seus episódios.

3 É o caso do contraexemplo inventado por Sosa para mostrar a insuficiência da sua segunda proposta de análise de 'obediência', a saber, uma situação ficcional na qual temos uma ordem cumprida por mero acaso e que, por conseguinte, não foi realmente obedecida: "Consider a fictional situation. The officer in charge of a training session addresses a student by the back door with the order: "Mr. So-and-so, will you close the door, please?" Mr. So-and-so, who has already felt the chill coming through the open door, was preparing himself to close it anyway; furthermore, because of an ear infection he was temporarily deaf and thus unable to hear the officer. (Afraid that his proneness to such infections would disqualify his from pilot training, he had kept his illness to himself and continued to attend classes as normally; he had trained himself to read lips and was proficient at it, but his head was turned when the instructor gave the order, and so forth.) Here Mr. So-and-so closes the door at $\mathrm{j}$ but he does not obey the order that he close the door at j" (Sosa, 1964, p. 45). 
natureza, mas sim da prática de esportes. Com isso, Sosa enfatiza a condição bem mais ampla das performances humanas, destacando ademais o vínculo entre conhecimento e ação. O exemplo privilegiado é o do tiro com arco, que entretanto só virá a aparecer em 2003, no texto "The place of truth in epistemology", quando ainda não tinha o formato posterior bastante completo, no qual pode ser avaliado em que variação de circunstâncias relativas a accuracy, adroitness e aptness o arqueiro é realmente bem-sucedido e, logo, em que variação dos aspectos da performance o sucesso do tiro depende do mérito do arqueiro, caso em que acertar o alvo manifesta sua competência enquanto arqueiro. ${ }^{4}$

Na primeira ocorrência em 2003, o traço em relevo foi a preferência do mérito sobre a sorte, que o modelo tanto preserva. Não aparece ainda, porém, a consideração central e delicada dos dois golpes de ar, nem tem função modelar de explicitar a célebre tripla dimensão AAA, ou seja, accuracy-adroitnessaptness. Poderemos bem apreciar sua transformação progressiva da condição de um exemplo entre outros à condição de modelo comum a todos os casos, sendo este um dos pontos passíveis de debate, importando-nos então identificar suas razões mais intrínsecas, que podem ser, como acreditamos, no mínimo concomitantes a alterações na compreensão de modalidades epistêmicas. ${ }^{5} \mathrm{De}$ todo modo, como um modelo, com ele testa a ductibilidade dos conceitos, como se fora um objeto técnico a encarnar as dimensões teóricas relevantes.

A manutenção do essencial do exemplo pode inclusive ser contestada, à medida que um aprofundamento pode trazer sim mudanças na obra, ao tornarse esta uma teoria. Agora, porém, basta-nos registrar seu ponto de chegada, a formulação mais recente e completa, com seu enfoque mais claro em uma estrutura comum a várias performances humanas, de sorte que, por esse viés, o exemplo se transforma em representante de todo um conjunto de estruturas análogas. No exemplo completo reproduzido a seguir, o tiro acerta o alvo e ele manifesta competência, mas não acerta o alvo por conta de sua competência

4 Quase literalmente, o texto é retomado no debate com Laurence Bonjour, publicado nesse mesmo ano, no livro Epistemic Justification: Internalism vs. Externalism. Foundations vs. Virtues. Sua formulação mais completa, com quase todos os aspectos explorados e quase todos levados em conta, só irá ocorrer em 2005, nas Locke Lectures. O modelo é repetido de forma sucinta em diversos artigos e conferências de Sosa, encontrando uma formulação elegante (como costuma ser a prosa de Sosa) e ademais atual (ou seja, afim no essencial à versão modelar de Epistemic Explanations) em Sosa (2011, p. 4).

5 Concordamos aqui com John Turri, que sinaliza bem este momento de inflexão na teoria do conhecimento de Sosa, conservando esta todavia a ideia essencial de ser o conhecimento uma crença verdadeira que deriva ou resulta de exercício de virtudes intelectuais. Nesse ponto, segundo Turri, a teoria teria tido um ganho, talvez então sobretudo em elegância e eficácia retórica, embora não somente. Cf. Turri, "Bi-level virtue epistemology", in Turri (2013, p. 159). Com a afirmação agora de uma teoria, segundo acreditamos, o modelo mostrará ainda mais sua força e centralidade. 
manifesta, ou seja, o sucesso ele mesmo não manifesta essa competência, pois ocorreu por um acaso. Um golpe de ar desviara a rota da flecha, mas um segundo golpe a reconduziu, de modo que o sucesso de modo algum pode ser atribuído ao arqueiro, mesmo sendo ele habilidoso. Chegamos assim à condição de exemplo privilegiado, mas, enfatize-se, de uma estrutura comum a vários arranjos télicos, que está no núcleo da teoria.

Reforcemos, mesmo com alguma repetição, o traço que completa o exemplo em suas formulações posteriores a 2005 e o preparam para a condição plena de um modelo da normatividade télica. O exemplo permite mostrar uma ocorrência possível de um tiro competente do sujeito e que, por acertar o alvo, seu sucesso manifestaria competência, mas que todavia não o faz, porque acerta o alvo por sorte. A flecha se dirigia corretamente ao centro do alvo quando um primeiro golpe de ar a afastou e, entretanto, um segundo golpe de ar a reconduziu ao centro do alvo, mas agora apenas por sorte e, enfatize-se, de modo completamente independente da competência do sujeito. Ou seja, o exemplo do arqueiro, entre várias possibilidades, mostra aquela situação em que, apesar de competente o sujeito e de haver sucesso, este não manifesta competência. Esse traço do exemplo é fundamental e, por ser inegociável, o torna modelar:

Archery provides a vivid example of that structure. If an archer shoots aiming to hit a certain target, we can assess that shot in various respects. First, does it succeed? Does it hit the target? Second, how competent is that shot? The arrow may exit the bow with an orientation and speed that would normally take it straight to the bullseye. Even if a gust diverts it, that shot may still be highly competent. It might thus be adroit without being accurate. And it can be accurate by luck, without being adroit. But even a shot that is both accurate and adroit might still underperform. An arrow adroitly released from a bow may be headed straight to the bullseye when a gust diverts it, so that it would now miss the target, except that a second gust puts it back on course. The archer succeeds in that attempt to hit the target, and the shot is also competent, as the arrow leaves the bow perfectly directed and with the right speed. But the shot is accurate because of the lucky second gust, not because of its adroitness. So, it is accurate and adroit without being apt. (Sosa, 2018, p. 18)

Agora, procurando descrever realizações aptas, ou seja, as que se dão mediante competência do agente e não apenas por sorte, o modelo relaciona conceitualmente cinco fenômenos principais e completamente integrados: attempt, success, competence, aptness, achievement. Dessa forma, ao ser generalizado o modelo para todas as tentativas, epistêmicas ou não, o modelo pode dar conta da normatividade télica das tentativas, enquanto inteligíveis em termos de sua accuracy, adroitness e aptness. O que o modelo faculta (ou tem como ponto de partida nada redutível) é uma analogia deveras esclarecedora 
entre performances atléticas (não apenas com o arco e flecha, mas também com o basquete, o baseball etc.) e performances epistêmicas (não apenas no nível do conhecimento animal, mas até ao pleno conhecimento reflexivo).

\section{3.}

O modelo parece funcionar mais ou menos como um Gleichnis, uma alegoria. Ou seja, na tradição wittgensteiniana, uma situação conceitual clara que ajudaria a ver relações mais confusas. Há objeções e dificuldades, é claro. Para forçar ainda mais a situação e encarar a dificuldade, a analogia se estende de modo geral a epistème e práxis, com o complemento de que, ao fim e ao cabo, tal como Sosa apresenta, o exemplo se torna mais que uma analogia, afirmando-se assim que a epistemologia das virtudes considera juízos e crenças judicativas como formas de práxis, no caso, de práxis intelectual: “[...] this is really more than an analogy: our virtue epistemology takes judgment and judgmental belief to be forms of praxis, of intellectual praxis" (Sosa, 2018, p. 51).

O que significa, porém, ser ainda mais que uma analogia? Seriam maiores as objeções que as já feitas à mera analogia? Se se trata de algo mais que uma analogia, não sendo essas dimensões obviamente idênticas, suponho que esteja afirmando que tenham a mesma natureza. Se têm a mesma natureza, de que ordem seria essa? Certamente, não coincide nos componentes físicos. Teriam então uma mesma estrutura? Ou seja, nessas dimensões, os componentes dos respectivos fenômenos a serem descritos ou analisados comportam-se categorialmente da mesma forma, segundo a mesma normatividade? Diríamos melhor que têm isso de essencial, a saber, que se comportam da mesma forma e se explicam suficientemente pelos mesmos conceitos-guia (attempt, success, competence, aptness e achievement), podendo ambas as dimensões (como casos de performances humanas) ser bem acomodadas no contexto de uma virtue theory, porquanto segundo esta valem essas considerações categoriais para o inteiro e geral domínio das performances humanas e, no caso de performances epistêmicas, estabelecem relações tanto na dimensão do assim chamado conhecimento animal quanto no conhecimento reflexivo, bem como ademais no pleno conhecimento reflexivo.

Uma crítica recente ao modelo foi apresentada por Paul Horwich - por sinal, em evento com o próprio Sosa. ${ }^{6}$ Não sem fundamento, Horwich aponta a 
fragilidade essencial de um modelo qualquer chamado a reunir elementos de uma gama bastante ampla - simplesmente, o conjunto das performances humanas voltadas a uma finalidade (e isso, veremos, com ou sem intencionalidade). No caso, como é de se esperar, o número de desanalogias sempre será superior ao número de analogias. Em sendo assim, um argumento como o de Horwich será demolidor, mas apenas caso as desanalogias toquem aspectos mais relevantes para o esclarecimento dos laços epistêmicos do que o fariam as analogias envolvidas, como procura responder Sosa.

Como se the antecipando avant la lettre o intento (de resto, previsível, pelas menções em Epistemology) de enunciação de uma teoria, Horwich esboça algumas críticas importantes. Ele percebe bem que o modelo do arqueiro adquiriu um estatuto por demais elevado; por isso, julga que o paralelismo com outras performances é enganador, havendo mais desanalogias que analogias entre os casos que o arqueiro exemplificaria, de sorte que não seria razoável modelar uma teoria do conhecimento com base em uma destreza plena com o arco e a flecha.

Podemos admitir a existência de desanalogias significativas, mas Horwich parece perder o ponto e exagera. É verdade que arcos exigem força, enquanto o conhecer não necessariamente. $\mathrm{O}$ tiro com arco determina-se por causas, $\mathrm{o}$ conhecer por razões. Um novato não reproduziria e repetiria um tiro perfeito, mas pode reproduzir uma argumentação, caso a compreenda. Ou melhor, diríamos de um tenista noviço que acaso respondeu muito bem a um serviço quase indefensável que o fez por pura sorte, mas não diríamos que por sorte um estudante reproduziu com eficácia a argumentação de seu professor; diríamos, sim, que ele a compreendeu.

Os casos irredutíveis em sua singularidade podem todavia ser iluminados pelas mesmas relações conceituais, essas sim modelares. Horwich parece, então, pedir mais do que Sosa está a oferecer-nos. Sem dúvida, é patente a dificuldade de erigir um modelo descritível causalmente para dar conta de um fenômeno cujos critérios internos são da ordem das razões; porém, não se trata disso. $\mathrm{O}$ arqueiro não executa uma performance mensurável, mas sim uma que permite a articulação, como citamos anteriormente, das ideias de attempt, success, competence, aptness e achievement. Não por acaso, portanto, Sosa precisa defender que seu alvo é um fenômeno de densidade metafísica, uma performance normativa, de modo que o exemplo amplia assim sua fecundidade explicativa, principalmente porque, enquanto modelo, retém 
variações estruturais que são elucidativas, apenas se reconhecidas caso a caso, não podendo ser inferidas.

A nosso ver, Horwich reduz o modelo a relações externas, como se fora uma base amostral para inferências de propriedades projetáveis entre casos que, todavia, não têm propriedades em comum, ou seja, retira o exemplo da condição de ser um modelo, que, como tal, é deveras instrutivo. Acreditamos, pois, ser possível defender que não se trata de uma analogia enganadora, a partir da qual basearíamos inferências condenadas a serem frágeis, sobretudo por tratar-se mesmo de um modelo, de sorte que a diferença entre os casos não afeta os aspectos limitados e deveras conceituais que articula.

Um caminho de resposta estaria, ao contrário, em situar o contexto da obra para além do enunciado de proposições. Reduzida a um conjunto descritivo e não normativo, a teoria teria dificuldades de prevalecer sobre descrições psicológicas rivais. Chega-se a comparar a bidimensionalidade central da teoria do conhecimento com a teoria dos dois sistemas cognitivos de Daniel Kahneman hoje tão em voga (cf. Turri, 2017, p. 159). Análise metafísica, porém, não é análise científica, mas antes, em seu caso, uma boa ousadia filosófica. O modelo é normativo, não meramente descritivo. Em certo sentido, é um exemplo de natureza gramatical, isto é, um exemplo que mostra a variabilidade e a ductibilidade dos laços entre os conceitos, permitindo-nos pensar a experiência.

Por razões dessa ordem, diante das ponderações e considerandos, Sosa não recua. Ao contrário, dá um salto avante ao coroar sua reflexão com a afirmação de uma teoria, concomitantemente destacando que sua análise, como afirma desde Judgment \& Agency, não é meramente linguística ou conceitual, mas sim metafísica. Ou seja, ele está disposto a pagar qualquer que seja o preço, firmando a posição estratégica de sua teoria da normatividade télica, que pareceria naturalmente voltar-se para o lado judicativo e reflexivo das considerações epistêmicas, ultrapassando inclusive o limite inicial do critério da intencionalidade:

But our teleological orientation and its telic normativity - enfatiza Sosa - can be extended to the epistemology of functional, animal knowledge. Our guiding concepts are the telic concepts of attempt, success, competence, aptness, and achievement, all of which span the distinction between attempts that are consciously intentional and those that are functionally teleological. (Sosa, 2018, p. 52)

A questão colocada por Horwich é relevante. Afinal, à primeira vista, as performances teriam grande diferença entre si, assim como pareceria um exagero Aristóteles ter aplicado sua teoria das quatro causas a produtos da natureza e produtos da cultura, à geração de um fruto e à confecção da escultura 
de uma deusa para enfeitar um templo. Diante dessas objeções, porém, Sosa bites the bullet e reafirma o traço comum de performances que são todas elas humanas e télicas, em seu essencial, valendo sim o modelo télico para dar conta da estrutura, com grande poder explicativo. A afirmação mais precisa, ampla e fecunda dessa estrutura é, decerto, uma das novidades que se associam à apresentação de suas posições na forma mais decidida de uma teoria, que, portanto, se volta ao esclarecimento desse fenômeno, e não se limita a uma análise linguística ou conceitual.

Como um projeto original, o modelo é passível ainda de críticas e deverá responder a muitas objeções. Por exemplo, se Horwich tiver razão, o modelo forçaria uma aproximação entre fenômenos com diferenças relevantes e talvez irredutíveis. Envolveria ademais a divisão do conhecimento em ordens distintas (animal, reflexivo e pleno), sofrendo talvez uma circularidade e um regresso ao infinito, ao solicitar aptidão de segunda ordem para "validar" a aptidão de ações de primeiro grau; e, em vez de sucesso no pretendido combate ao ceticismo, terminaria por alimentar ilações céticas. A críticas como essas, Sosa responde agora avançando em sua intuição originária, consolidando-a em uma teoria, bastante cioso das articulações entre os conceitos que o modelo vincula para dar conta do fenômeno das performances.

\section{4.}

De todas as ações intencionais, compreendidas como performances humanas, as mais nobres visariam ao conhecimento. ${ }^{7} \mathrm{O}$ conhecimento na obra de Sosa (não de um golpe, mas cumulativamente) seria classificado e definido da seguinte forma, de modo que as quatro primeiras cláusulas seriam satisfeitas havendo conhecimento animal; as seis primeiras, havendo conhecimento reflexivo; e as oito em conjunto, havendo pleno conhecimento reflexivo: ${ }^{8}$

$\mathrm{S}$ plena e reflexivamente sabe que $<\mathrm{p}>\equiv$

(1) $\mathrm{S}$ acredita que $<\mathrm{p}>$

(2) $<$ p $>$ é verdadeira (ou seja, a crença acerta com a verdade)

(3) S tem a propensão (competência, faculdade) de formar crenças confiavelmente verdadeiras

7 Nada a estranhar nessa aproximação tão extrema entre conhecimento e outras performances. Como afirma em texto dos mais recentes, "Knowledge is a form of action, to know is to act, and knowledge is hence subject to a normativity distinctive of action, including intentional action" (Sosa, 2017, p. 207).

8 Servimo-nos aqui, com muitas adaptações, da síntese proposta por Paul Horwich, em seu "Sosa's theory of knowledge", p. 2. 
(4) $\mathrm{O}$ acerto de $\mathrm{S}$ em acreditar que $<\mathrm{p}>$ é amplamente explicado por esse sucesso manifestar sua propensão/competência

Até aqui, com as cláusulas que seriam juntas suficientes e individualmente necessárias para o conhecimento animal, teríamos a base para a apresentação de uma definição de conhecimento capaz de superar os impasses iniciais originados pelo problema de Gettier, embora não os impasses decorrentes do programa de investigação, esses bem mais sofisticados. Afinal, a definição já é suficiente para mostrar que uma crença que falha em ser conhecimento não expressa o exercício adequado de virtudes intelectuais e, afinal, é melhor acertar com a verdade do que errar, mas, além disso, é decisivo que acertemos com a verdade por nossos méritos e não por mera sorte. A definição de conhecimento destaca outros traços, por meio dos quais descortinamos um cenário mais enriquecido do exercício de nossa liberdade cognitiva. Assim, S conhece plena e reflexivamente se, ademais:

(5) $\mathrm{S}$ acreditar que $<\mathrm{p}>$ é um ato intencional

(6) A intenção que sustenta esse ato é a de acreditar em algo verdadeiro, de acertar com a verdade

(7) $\mathrm{S}$ acredita (intencionalmente) que a propensão que sustenta a crença de que $<\mathrm{p}>$ é confiável

(8) O acerto dessa crença na confiabilidade é amplamente explicado por ela também manifestar uma propensão confiável para formação de crenças.

Podemos traduzir essas cláusulas, que, a partir da distinção fundamental entre conhecimento animal e conhecimento reflexivo, perfazem então três graus do conhecimento, por meio dos quais Sosa acredita oferecer uma resposta satisfatória e produtiva para nossos desafios epistêmicos. Conhecimento, então, envolve níveis distintos de performance, com o que a noção de teoria da normatividade télica consolida e aprofunda a noção anteriormente desenvolvida (por exemplo, em Knowing Full Well) de conhecimento reflexivo pleno como centro de uma performatividade normativa.

As cláusulas, sendo individualmente necessárias e conjuntamente suficientes para um pleno conhecimento reflexivo, respondem distributiva e coletivamente pela ideia de que o conhecimento é superior à mera opinião verdadeira. Ou seja, para satisfazer a condição de haver conhecimento animal, deve estar dado que a verdade prefere sobre a falsidade, que o sujeito crê então nisso que é verdadeiro e, ao crer, ele está na condição de poder crer que é verdadeiro, validando a verdade da crença o modo de crer do sujeito. Em um nível superior, reflexivo, que incorpora as condições anteriores, a 
crença de que $<\mathrm{p}>$ deve ser intencional, de sorte que por essa intenção visa-se à verdade, no que se confirma sua preferência sobre a falsidade. Enfim, para haver pleno conhecimento reflexivo, além das cláusulas anteriores, o sujeito deve confiar intencionalmente em sua confiabilidade, manifestando o acerto dessa confiabilidade a propensão em formar crenças confiáveis.

Esse gesto taxonômico descreve teses sobre o fenômeno do conhecimento e culmina em uma teoria. Entretanto, a descrição não compete com alguma teoria psicológica, porquanto normativa e, por isso mesmo, é sobretudo filosófica, no sentido wittgensteiniano de cuidar das condições de organização da experiência e de lidar com modalidades epistêmicas, não sendo um acaso (como pretendemos mostrar) que a constituição de uma teoria da normatividade télica aproxime Sosa ainda mais das posições de Wittgenstein no Da Certeza, mediante uma "epistemology of default assumptions". Com efeito, Sosa acredita que a noção de default assumptions possibilita um novo e vigoroso tratamento às dificuldades aludidas pelo ceticismo filosófico, pois o cético equivocar-se-ia acerca do que é requerido para garantir a qualidade epistêmica de nossos juízos e crenças ordinários.

Mas o que quer isso dizer? O que acrescenta, afora dizer que um conhecimento tende a ser um conhecimento, tem tudo para ser um conhecimento? No fundo, a descrição do fenômeno do conhecimento reforça a ideia de que seriam muitíssimo improváveis as chances das viradas fantásticas dos cenários céticos, nos quais, por não termos uma visão divina, não é certo que tenhamos chegado à versão final e completa dos fatos. Em todas as reviravoltas possíveis, todas só seriam porventura contornadas a partir de um olhar divino, o único garantido, quando tudo o mais é caprichoso. Entretanto, à luz de uma abordagem normativa mas também pragmática, o conhecimento também se faz com caprichos, com riscos relativos, que exatamente estão na margem de segurança com que estamos dispostos a lidar e conviver. $\mathrm{O}$ conhecimento não se obtém, afinal, para calar o cético, mas sim para seguir a vida.

\section{5.}

Não poderíamos discorrer aqui sobre todos os pontos envolvidos na reconstituição e análise das condições e do sentido de uma teoria da normatividade télica. Destaquemos, porém, muito brevemente, um ponto essencial de sua inspiração como resposta ao problema de Gettier, em sua correlação com modalidades epistêmicas, que aproximam esta última virada da epistemologia das virtudes das considerações wittgensteinianas, equivalentes ou próximas a uma epistemologia das default assumptions. 
O lema máximo do problema de Gettier parece consistir na ideia de que a sorte sempre bloquearia o conhecimento. Há então uma série de exemplos e contraexemplos que visam a dificultar a formulação de uma quarta cláusula para o problema de Gettier, uma que evite basear-se a justificativa da opinião verdadeira em uma falsidade, ou que garanta um laço causal entre justificativa e conhecimento proposicional, ou ainda que rastreie o vínculo entre conhecimento e condições dadas no mundo, ou enfim que mostre o exercício de virtudes intelectuais, de sorte que o sujeito atinja a verdade por causa dessa competência epistêmica. ${ }^{9}$ Com a teoria, Sosa pretende dar resposta a todos os contraexemplos, inclusive os mais resistentes, como é o caso de Barney (que diz ser um estábulo o que de fato é um estábulo, mas numa região de estábulos falsos) ou o caso, talvez semelhante a este, ${ }^{10}$ de Simone, que acerta seus tiros mas não distingue se está em um simulador de voo ou em uma cabine de avião - situação que, por sinal, lembra bastante a de alguns cenários céticos (cf. Sosa, 2016, capítulo 6).

A verdade obtida por mero acaso é verdade, mas não conhecimento. Esse, pois, o problema de Gettier. Como identificar então o mérito que torna conhecimento o enunciado verdadeiro? A epistemologia das virtudes faria aí duas coisas, contra uma perspectiva olímpica (e cética) do conhecimento. Primeiro, mostraria o que caracteriza esse tipo de sorte e, logo, em segundo lugar, mostraria também que, enfatize-se, a sorte nem sempre bloqueia o conhecimento, mas sim, portanto, apenas aquela que se choca com a procura do sujeito em acertar com a verdade mediante competência própria para obtenção do conhecimento dessa verdade:

Of course, not just any kind of luck affects the quality of an attained success, of an achievement. It may be lucky that the achiever retains his skill, is in good shape or well situated, or is even alive. Many essential elements of achieve- ment can depend on luck that does not diminish achievement. (Sosa, 2017, p. 217)

A sorte nem sempre bloqueia o conhecimento. Tratando-se o conhecimento de uma performance, de um exercício de competência que se manifesta no

9 Contrapondo-se às soluções como as de Alvin Goldman e Robert Nozick, Sosa substitui (em "How to defeat opposition to Moore") o critério da sensibilidade modal por seu falso contrapositivo, o critério de segurança modal, que depois abandona, com sobradas razões, como aponta Turri: "The AAA-model subverts the safety requirement because a performance could be apt without also being safe. Indeed, it turns out that a performance can be apt despite being extremely unsafe" (Turri, 2013, p. 160). Mesmo sendo uma "aberração", no dizer de Turri ("The addition of safety in the interim was an aberration", in Turri, 2013, p. 161), a safety modal teve lá seus bons motivos: "Like sensitivity, safety also aims to capture our intuition that knowledge is non-lucky true belief, the guiding interpretation of that intuition being that one's true beliefs should, if they are to count as knowledge, be safe in the sense that they could not easily have been false" (Pritchard, 2010, p. 734).

10 Isso é algo que nossa pesquisa precisa aprofundar, pois não nos parece haver resposta unívoca em Sosa. 
acertar com a verdade, ele tem níveis de competência, nem todos bloqueados pela interferência do acaso. A epistemologia das virtudes continua assim dando conta dos casos clássicos de Gettier, mas agora, afastando a exigência modal de segurança em favor de uma segurança efetiva, dá conta também de exemplos extraordinários que, por assim dizer, estavam escapando pelos dedos, como os casos de Barney e Simone.

Também a exigência de segurança para a aptidão é agora a de uma segurança atual (talvez até por sorte) e não modal. Assim, a mera probabilidade de um golpe de ar não retira a competência, se um golpe de ar efetivo não interveio, pois uma performance apta não é dependente de quão seguramente alguém possui a competência relevante. Não basta ter o triplo AAA garantido, se não há juízo adequado do triplo SSS (competência aqui definida por condições adequadas de skill, shape e situation) - ou seja, exatamente o que escapa a Simone e a Barney, que não podem discernir se têm a condição adequada para exercitar a tripla normatividade télica:

We can now respond that Simone's knowledge is on the animal level but falls short. Knowledge full well requires apt belief, or fully apt representation. It requires, therefore, not only apt representation, but also, on the second order, apt grasp (at least in the form of apt presupposition) that one's first-order representation is apt, where the accuracy of this second-order attitude must then manifest the believer's second-order competence. ${ }^{11}$ (Sosa, 2015, p. 148)

Os três graus do conhecimento (com suas oito cláusulas) não constituem, portanto, uma mera taxonomia (uma qualquer resultante do impulso analítico de sempre to distinguish and label), mas sim uma investigação normativa, uma busca de todo teórica que supera sucessivos obstáculos conceituais. Tampouco constituem uma saída apenas conceitual, pois buscam identificar um núcleo fenomenal efetivo, próprio de um conjunto de performances humanas e, logo, substancialmente intencionais.

Sosa pretende que essa visão do conhecimento (visão, digamos, de bom enxadrista $)^{12}$ pode operar em vários níveis, sendo um eficaz antídoto contra o ceticismo. Por conta disso, julga dever aprofundar sua aproximação com

11 A solução do problema de Gettier, em vez de contrapor a competência específica de um sujeito ao olhar daquele que tudo vê, leva Sosa a uma visão bidimensional e depois tridimensional do conhecimento. Conhecer não é termo unívoco. Erra talvez, por exemplo, quem aceita o conflito para decidir se Barney tinha ou não conhecimento ao identificar corretamente o estábulo, pois afinal ele o tinha, exerceu aí sua competência, mas não tinha segurança efetiva dos contornos da situação, não tinha critério para afastar os casos das meras fachadas.

12 Aludimos aqui ao modo com que Wittgenstein resolve o paradoxo cético envolvido no problema do seguir uma regra, comparando-o com o Gleichnis por ele utilizado do jogo de xadrez. Cf. Salles, 2012. 
Wittgenstein - questão que, como dissemos, configura uma das hipóteses de nosso trabalho. Ou seja, Sosa adota postura semelhante à enunciada no $§ 509$ do livro Da Certeza, com a qual Wittgenstein lembra-nos que, ao fim e ao cabo, um jogo de linguagem não começa pela dúvida. Ao contrário, ele só é possível se confiamos em alguns dados. E aqui vale a ênfase: "se alguém confia em algo (Eu não disse 'pode confiar em algo')" (Wittgenstein, 1975, § 509, grifos nossos).

Sosa adota estratégia semelhante, após colocar em planos similares o juízo (afirmativo ou negativo) e a suspensão do juízo, sendo medidas ambas as posturas pelos riscos que o agente epistêmico pode julgar-se obrigado a aceitar. E aqui a teoria da normatividade télica simplesmente deve suprimir o suposto privilégio que a dúvida cética deveria ter sobre a certeza pragmática. Como um agente, a suspensão do juízo deve resultar de quão competentemente julga poder confrontar-se com o risco pertinente, não havendo razão a priori para supor que o risco envolvido na suspensão seria preferível à decisão pragmática padrão de assumir o risco apropriado:

A performance of a nighttime athlete can be apt even if extremely unsafe (because of
the unsafe standing of the lighting system). And a similar conclusion may be drawn
about epistemic performances, in which again great danger, great risk of failure, seems
quite compatible with success that is perfectly apt. Only the lack of safety involving
"relevant" alternatives can deny us knowledge. (Sosa, 2017, p. 221n.)

A teoria da normatividade télica transforma uma certa descrição da performance humana em modelo capaz de explicar o conhecimento, dando supostamente conta de todos os impasses gettierescos anteriores. Não sendo uma mera descrição de um fenômeno, é o resultado de uma produção filosófica específica, a saber, de uma análise (como dirá Sosa) metafísica, que conta para ela com vários pressupostos e ganhos conceituais urdidos ao longo da obra. Não é de estranhar que, entre suas condições, encontra-se uma visão específica de modalidades epistêmicas, não sendo um mero acaso que o exemplo canônico do sistema, a descrição do desempenho competente ou não de um arqueiro, apareça apenas após o enfrentamento por Sosa do debate sobre sensitivity e safety, tendo também sua transformação de exemplo em paradigma relação clara com mais uma virada modal, com o subsequente acréscimo de questões relativas à relevância do conhecimento.

A teoria afirmar-se-ia assim como uma resposta aos riscos denunciados por tantos oponentes de um círculo vicioso ou de uma regressão ao infinito, mas também como uma proposta madura de enfrentamento das ilusões do ceticismo pirrônico. E não é trivial nossa hipótese. Afinal, a ocorrência do exemplo bem 
poderia ser uma coincidência, um golpe de sorte externo, e não uma necessidade interna da obra. Por casual que seja a origem, é essencial a instalação do exemplo na trama conceitual da obra, perfazendo assim a constituição de uma teoria da normatividade télica um movimento semelhante ao que levou à própria proposição seminal da epistemologia das virtudes em "The Raft and the Pyramid", que então respondia às dificuldades de compreensão e sustentação do conhecimento, quer pelo fundacionismo, quer pelo coerentismo.

Isso bem é o que desejamos apresentar, procurando recuperar a démarche da obra e não apenas a sequência de ideias defendidas. Com isso, constituindo um todo, ao tempo que se transforma, a obra revela um estilo singular, um modo todo próprio de Sosa em responder aos desafios epistemológicos, que não é um simples eco da sequência de debates de que participou. Uma obra, afinal, é também ela uma espécie de performance, derramada no tempo, tendo objetivo duplo de chegar à verdade com domínio dos meios por que chega à verdade, de sorte que exemplifica, nos graus possíveis de performance epistêmica, um pleno conhecimento ultrarreflexivo.

Uma obra como a de Sosa, em permanente estado de esboço, caminha enfim para configurar uma teoria, que, todavia, queremos crer, não pretende competir com teorias psicológicas acerca dos tipos de conhecimento ou dos modos da ação humana. Não é dado ademais que a obra já tenha encontrado fórmulas definitivas. Com certeza, porém, será uma teoria singular, na qual a análise do fenômeno não anulará análises conceituais e linguísticas, onde sempre haverá espaço para experimentos de pensamento, para a surpresa diante de twists repentinos, para o desafio de exemplos mais refinados. Let's tweak our example, parece ser o mote constante de Sosa, o modo de respiração da obra, que aprendeu a avançar e a surpreender com soluções originais nunca fechadas, mas antes dispostas como um convite filosófico ao debate.

\section{Referências}

ANSCOMBE, G. E. M. "Intention”. Oxford: Blackwell, 1963.

DANCY, J., SOSA, E., STEUP, M. (eds.). “A Companion to Epistemology”. Oxford: Wiley Blackwell, 2010.

GETTIER, E. "Is justified true belief knowledge?". Analysis, 23, 1963, pp. 121-123. HORWICH, P. "Sosa's theory of knowledge". Synthese, 2018 (online https://link.springer. com/content/pdf/10.1007/s11229-018-1697-8.pdf, acessado em 01 de julho de 2018). PRITCHARD, D. "Sensitivity and Safety". In: DANCY, J., SOSA, E., STEUP, M. (eds.). A Companion to Epistemology, 2010.

SALLES, J. C. "O cético e o enxadrista: Experiência e significação em Wittgenstein". Coleção Empiria, Salvador: Quarteto, 2012. 
SOSA, E. "Directives: A logico-philosophical inquiry". University of Pittsburgh, 1964. . "Knowledge in Perspective". Cambridge, UK: Cambridge University Press, 1991. . "How to Defeat Opposition to Moore". Philosophical Perspectives, 13, 1999, pp. 141-53.

. "The place of truth in epistemology". In: DEPAUL, M., ZAGZEBSKI, L. (eds.). Intellectual virtue: Perspectives from ethics and epistemology. New York: Oxford University Press, 2003.

. “A Virtue Epistemology: Apt Belief and Reflective Knowledge”. Oxford: Oxford University Press, 2007.

. "Knowing Full Well”. Princeton: Princeton University Press, 2011.

. "Judgment \& Agency". Oxford: Oxford University Press, 2015.

. "Epistemology". Princeton: Princeton University Press, 2017.

. "Epistemic explanations: A theory of telic normativity, and what it explains".

Mimeo, 2018.

SOSA, E., BONJOUR, L. "Epistemic Justification”. Oxford: Blackwell, 2004.

TURRI, J. "Virtuous Thoughts: The Philosophy of Ernest Sosa”. Dordrecht: Springer, 2013.

WITTGENSTEIN, L. "On Certainty”. Oxford: Blackwell, 1975. 